Journal of Biotechnology and Strategic Health Research

\author{
Araştırma Makalesi / Research Article
}

http://dergipark.org.tr/tr/pub/bshr

\title{
Dental İmplant Uygulamalarında Yumuşak Doku Cerrahi Gereksiniminin Değerlendirilmesi
}

\section{Evaluation of Soft Tissue Surgery Requirement in Dental Implant Applications}

\section{(iD) Ebru Sağlam ${ }^{1}$, Nesrin Saruhan ${ }^{2}$}

${ }^{1}$ Sağlık Bilimleri Üniversitesi Diş Hekimliği Fakültesi Periodontoloji Anabilim Dalı, İstanbul, Türkiye. 2 Eskişehir Osmangazi Üniversitesi Diş Hekimliği Fakültesi Ağız, Diş ve Çene Cerrahisi Anabilim Dalı, Eskişehir, Türkiye. ORCID ID: Ebru Sağlam https://orcid.org/0000-0002-7329-8085, Nesrin Saruhan https://orcid.org/0000-0003-1160-4179 ${ }^{\star}$ Sorumlu Yazar / Corresponding Author: Ebru Sağlam, e-posta / e-mail: saglam.ebru@yahoo.com Geliş Tarihi / Received : 05-05-2021 Kabul Tarihi / Accepted: 21-05-2021 Yayın Tarihi / Online Published: 30-08-2021

Sağlam E., Saruhan N. Dental İmplant Uygulamalarında Yumuşak Doku Cerrahi Gereksiniminin Değerlendirilmesi, J Biotechnol and Strategic Health Res. 2021;5(2):113-118

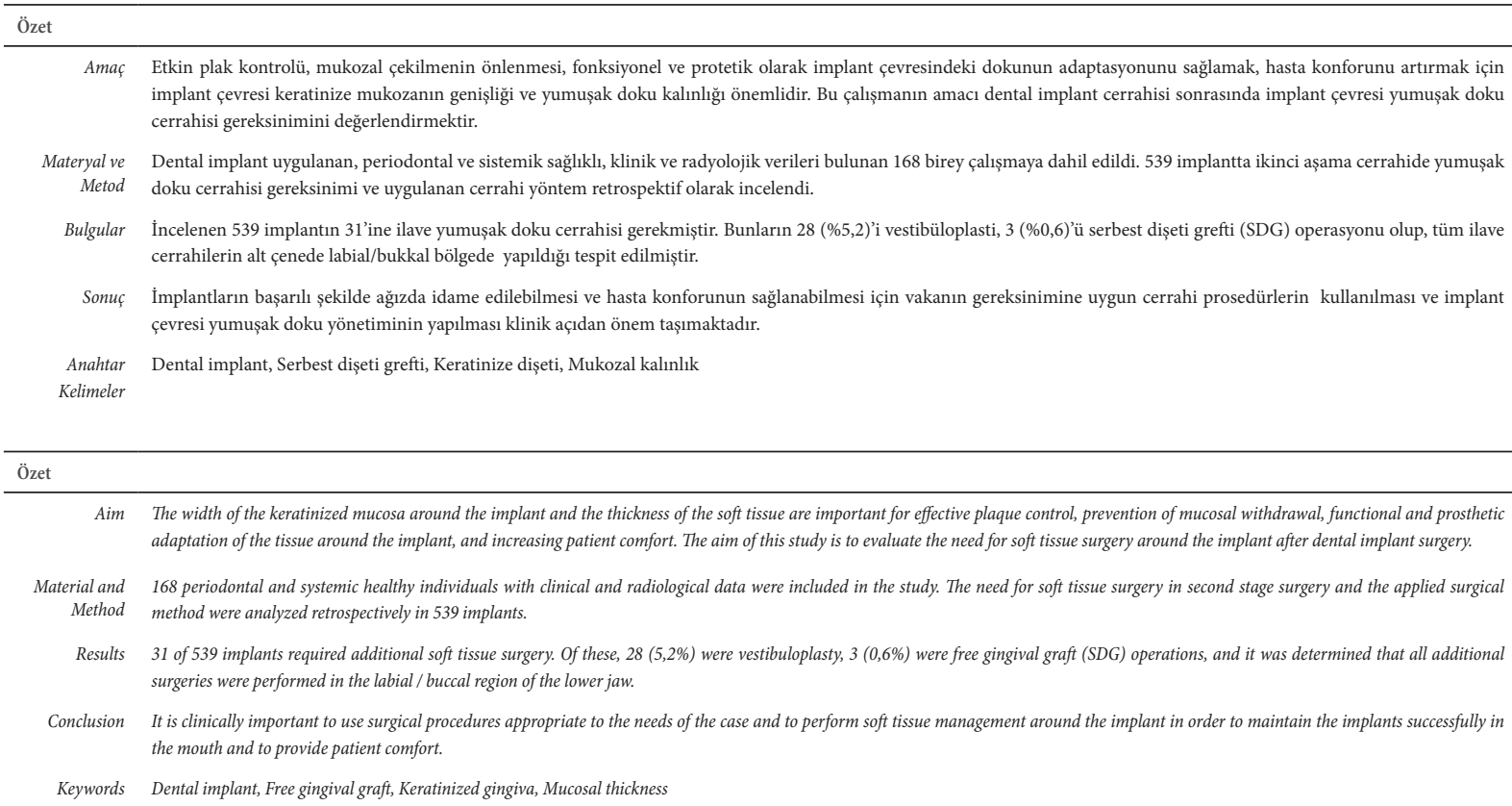

Results 31 of 539 implants required additional soft tissue surgery. Of these, 28 (5,2\%) were vestibuloplasty, $3(0,6 \%)$ were free gingival graft (SDG) operations, and it was determined that all additional surgeries were performed in the labial / buccal region of the lower jaw.

Conclusion It is clinically important to use surgical procedures appropriate to the needs of the case and to perform soft tissue management around the implant in order to maintain the implants successfully in the mouth and to provide patient comfort.

Keywords Dental implant, Free gingival graft, Keratinized gingiva, Mucosal thickness 


\section{GIIRIŞ}

Dental implant uygulamaları günümüzde tam veya kısmi dişsizlik durumlarının tedavisinde yaygın şekilde kullanılmaktadır. Dental implantların estetik ve fonksiyonel olarak uzun süreli başarısında implant çevresi sert ve yumuşak dokuların sağlıklı şekilde idame edilebilmesi oldukça önemlidir ${ }^{1} 2017$ Word Workshop Periodontal ve Peri-implant Hastalık sınıflandırmasında da bir başlık oluşturan sert ve yumuşak doku eksikliklerine bağlı olarak zayıf plak kontrolü, peri-implanter mukozanın inflamasyonu, çekilmesi ve kemikte yıkım meydana gelebilmekte$\operatorname{dir}^{2-4}$.

Sert ve yumuşak doku yetersizlikleri implant cerrahisi sonrasında oluşabildiği gibi cerrahi öncesinde de mevcut olabilmektedir ${ }^{5}$. İmplant çevresindeki keratinize mukoza genişliği ve yumuşak doku kalınlığı implant çevresi krestal kemik kaybı ve diş eti çekilmesi için önemli risk faktörleri olan yumuşak doku yetersizliklerindendir ${ }^{5,6}$. Günümüzde henüz implant çevresi keratinize mukoza genişliği ve yumuşak doku kalınlığ 1 için mm cinsinden kritik bir eşik değer belirtilememektedir ${ }^{1,5,7}$. Ancak plak kontrolünü kolaylaştırmak, mukozal çekilmeyi önlemek, fonksiyonel ve protetik olarak implant çevresindeki dokunun adaptasyonunu sağlayarak hasta konforunu artırmak için anahtar faktörler olarak görülmektedirler ${ }^{1,7-10}$.

Peri-implant plastik cerrahi teknikler, implant rehabilitasyonu sırasında ve sonrasında gelişen sert ve yumuşak doku problemlerini önleyebilir ${ }^{11}$. Bu teknikler aracıllğı ile implant çevresi keratinize mukozanın genişliğinin ve yumuşak doku kalınlığının artılması sağlanabiliir, ${ }^{8,11,12}$. Apikale pozisyone flap, laterale pozisyone flap, serbest dişeti greftleri (SDG) implant çevresi keratinize mukoza genişliğini artırmak için yaygın olarak kullanılan tekniklerdir ${ }^{3,12-15}$. İmplant çevresi yumuşak dokunun kalınlığını artırmak için de sıklıkla otojen bağ dokusu greftleri tercih edilmektedir ${ }^{8,12}$. Bu çalışmada iki aşamalı dental implant cerrahisi sonrasında implant çevresi yumuşak doku yönetimi gereksinimini değerlendirmek amaçlanmıştır.

\section{YÖNTEM}

Çalışma için Eskişehir Osmangazi Üniversitesi Girişimsel Olmayan Etik kurul başkanlığından onay alındı (Karar No:2020-346). Çalışmamıza Eylül 2017 ile Haziran 2020 tarihleri arasında kliniğimize dental implant tedavisi için başvuran hastalar dahil edildi. 168 hastada bulunan 539 implantın verileri restrospektif olarak değerlendirildi.

\section{Dahil Edilme Kriterleri}

- 18 yaşından büyük olan,

- Dental implant tedavisi uygulanan,

- Periodontal olarak sağlıkl,

- < 2mm keratinize dişeti genişliği olan ve implant çevresi dişeti sağlığının klinik olarak sürdürülemediği,

- Radyolojik ve klinik verilerine ulaşılabilen hastalar çalışmaya dahil edildi.

\section{Hariç Tutma Kriterleri}

- Kontrolsüz diabet, osteoporoz, hematolojik bozukluklar gibi sistemik hastalık bulunan hastalar çalışma dışı bırakıldı.

\section{İstatistiksel analiz}

Elde edilen verilerin istatistiksel analizleri IBM SPSS Statistics 20 paket progrmaı (IBM Corp, Armonk, NY) kullanılarak gerçekleştirildi. Verilerin değerlendirilmesinde, tanımlayıcı istatistiklerden yararlanıldı.

\section{SONUÇ}

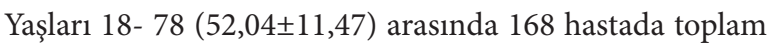
539 implant değerlendirildi. Bireylerin 271'i $(\% 50,3) \mathrm{ka}-$ dın, 268'i (\%49,7) erkekti. Değerlendirilen bölgelerin 295’i (\%54,7) üst çenede, 244'ü $(\% 45,3)$ alt çenede idi. İmplantların 149'sı (\%27,6) anterior bölgede (74'ü üst çene, 75'i alt çene), 390' 1 ise $(\% 72,4)$ posterior bölgede (221'i üst çene, 169 'u alt çene) bulunmaktaydı. Çalışmaya katılan bireylerin cinsiyet, implant uygulanan çene ve bölgelerin dağılımları ve oranları Tablo- 1'de gösterilmiştir. 
J Biotechnol and Strategic Health Res. 2021;5(2):113-118

SAĞLAM, SARUHAN, Dental İmplant Uygulamalarında Yumuşak Doku Cerrahi Gereksiniminin Değerlendirilmesi

Tablo 1: Bireylerin cinsiyet, implant uygulanan çene ve bölgelerinin tanımlayıcı istatistikleri

\begin{tabular}{|l|c|c|}
\hline \multicolumn{2}{|c|}{} & $\mathrm{n}(\%)$ \\
\hline \multirow{3}{*}{ Cinsiyet } & Kadın & $271(\% 50,3)$ \\
\cline { 2 - 3 } & Erkek & $268(\% 49,7)$ \\
\hline \multirow{3}{*}{ Çene } & Üst Çene & $295(\% 54,7)$ \\
\cline { 2 - 3 } & Alt Çene & $244(\% 45,3)$ \\
\hline \multirow{2}{*}{ Bölge } & Anterior & $149(\% 27,6)$ \\
\cline { 2 - 3 } & Posterior & $390(\% 72,4)$ \\
\hline
\end{tabular}

Değerlendirilen 539 implantın 28 (\%5,2)'ine vestibüloplasti, 3 (\%0,6)'üne SDG yapıldı̆̆ı, 508 (\%94,2)'sine ek cerrahiye gerek kalmadığı tespit edilmiştir. Vestibüloplasti ve SDG uygulamalarının tamamının alt çenede yapıldığ1 ve tümünün labial/bukkal bölgede uygulandığ1 görülmüștür. Vestibüloplasti işleminin 18 (\%64,3)'i kadın, 10
$(\% 35,7)$ 'u erkeklerde, SDG'lerin hepsi ise kadın bireylerde gerçekleştirilmiştir. Uygulanan bölge açısından incelendiğinde vestibüloplasti işleminin 24 (\%85,7)'ü anterior, 4 $(\% 14,3)$ 'ü posteriorda, SDG işleminin $1(\% 33,3)$ 'i anterior, 2(\%66,7)'si posterior bölgede gerçekleştirilmiştir. Yumuşak doku cerrahisi uygulanan implantların dağılımları ve oranları Tablo-2'de gösterilmiştir.

Yaş ortalamaları ve uygulanan ek cerrahi işlemler incelendiğinde; ek cerrahi gerekmeyen bireylerin yaş orta-

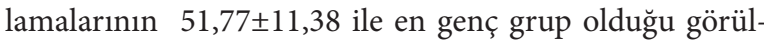
müştür. Yaş ortalamaları vestibüloplasti uygulanan grupta $56,07 \pm 12.46$, SDG uygulanan grupta $60,67 \pm 9,81$ olarak respit edilmiştir.

\begin{tabular}{|l|c|c|c|c|}
\hline \multicolumn{2}{|c|}{ Tablo 2: Yumuşak doku cerrahisi uygulanan implantların tanımlayıc1 istatistikleri } \\
\hline & & $\begin{array}{c}\text { Cerrahi Uygulanmayan } \\
\mathbf{n}(\%)\end{array}$ & $\begin{array}{c}\text { Vestibüloplasti } \\
\mathbf{n}(\%)\end{array}$ & $\begin{array}{c}\text { SDG } \\
\mathbf{n}(\%)\end{array}$ \\
\hline \multirow{2}{*}{ Toplam n (\%) } & $508(\% 94,2)$ & $28(\% 5,2)$ & $3(\% 0,6)$ \\
\hline \multirow{2}{*}{ Cinsiyet } & Kadın & $250(\% 49,2)$ & $18(\% 64,3)$ & $3(\% 100)$ \\
\hline \multirow{2}{*}{ Çene } & Erkek & $258(\% 50,8)$ & $10(\% 35,7)$ & $0(\% 0)$ \\
\hline \multirow{2}{*}{ Bölge } & Üst çene & $295(\% 58,1)$ & $0(\% 0)$ & $0(\% 0)$ \\
\cline { 2 - 5 } & Alt çene & $213(\% 41,9)$ & $28(\% 100)$ & $3(\% 100)$ \\
\cline { 2 - 5 } & Anterior & $124(\% 24,4)$ & $24(\% 85,7)$ & $1(\% 33,3)$ \\
\cline { 2 - 5 } & Posterior & $384(\% 75,6)$ & $4(\% 14,3)$ & $2(\% 66,7)$ \\
\hline
\end{tabular}




\section{TARTIŞMA}

Osseoentegre dental implantların uzun dönem klinik başarısı açısından implant çevresi keratinize dişeti genişliği ve yapışık dişeti hacminin önemi hala tartışmalı olsa $\mathrm{da}^{15-}$ ${ }^{17}$, günümüzde keratinize dişeti genişliği ve yumuşak doku hacmindeki yetersizliğin, daha çok plak birikimine, artmış doku enflamasyonuna ve mukozal çekilmeye hatta ataçman kaybına yol açtığı görüşü ağırlık kazanmışıı5,9,12,18. İmplant çevresi yumuşak doku dolayısı ile de sert doku sağlığının korunabilmesi ve tedavisi için peri-implanter plastik cerrahi uygulamaları gerekebilmektedir ${ }^{1,12}$. Yumuşak doku yönetiminde kullanılan bu plastik cerrahi tekniklerin implant cerrahisi öncesinde mi yoksa sonrasında $\mathrm{m}$ ı geçekleştirilmesinin daha ideal olduğu henüz netlik kazanmamıştır ${ }^{16,19,20}$. Lin ve ark. ${ }^{21}$ sistematik derlemelerinde implant tedavileri sırasında eş zamanlı ve aşamalı yumuşak doku ogmentasyonu arasında bir fark olmadığını, her iki yöntemde de keratinize doku genişliği ve yumuşak doku kalınlığında önemli artış elde edilebildiğini belirtmişlerdir ${ }^{21}$. Çalışmamızda dental implant uygulanmış 168 hastada 539 implantın 31'inde implant cerrahi sonrasında iyileşme başlı̆̆ yerleştirilmesi sırasında implant çevresi yumuşak doku cerrahisi uygulanmıştır.

İkinci aşama cerrahide dental implantların etrafında keratinize dişeti ve yumuşak doku hacmi kazanmak için SDG, subepitelyal bağ dokusu greftleri, serbest periosteal greftler, apikale pozisyone yarım kalınlıklı flap, vestibüloplasti ve bunların kombine kullanımları gibi farklı cerrahi teknikler mevcuttur. Hangi tekniğin kulanılması gerektiğine dair bir görüş birliği yoktur. Vakanın gereksinimine, hekimin tercihine göre uygun cerrahi prosedüre karar verilmektedir ${ }^{1,12,15,16,20,22}$. Baltacioğlu ve ark. ${ }^{11} 20$ hastada yaptıkları çalışmada 86 implanttan 41 'inin çevresine keratinize doku genişliğini artırmak için iki aşamalı cerrahi öncesinde veya sonrasinda SDG veya serbest periostal greft uygulamışlardır. Tüm vakalarda yeterli keratinize doku $(>2 \mathrm{~mm})$ elde ettiklerini belirtmişlerdir. Asıl amaç keratinize dişeti genişliğini artırmak olsada kullanılacak tekniği (SDG/subperiosteal greft) implant rehabilitasyo- nundaki tedavi protokollerine ve klinisyen seçimlerine göre belirlediklerini bildirmişlerdir. Ayrıca SDG/SPG cerrahisi gerek görülmeyen diğer dental implant bölgelerindeki peri-implant doku sağllğının korunmuş olmasında yeterli keratinize dişeti genişliğine sahip olmanın önemini vurgulamışlardır ${ }^{11}$. Çalışmamızda yumuşak doku yönetimi için yapılan tüm cerrahi işlemler ikinci aşama cerrahide gerçekleştirilmiştir. Hamurcu ve ark. ${ }^{22} 5$ olgu sunumu paylaştıkları çalışmalarında implant çevresinde sığ vestibül sulkus ve yetersiz $(<2 \mathrm{~mm})$ keratinize dişeti genişliği bulunan vakalarda ikinci aşama cerrahide serbet dişeti grefti veya SDG+ vestibüloplasti yöntemlerini, yumuşak doku hacmi artırmak içinde subepitelyal bağ dokusu grefti uygulamışlardır. Çalışmamızda da literatüre benzer şekilde vestibüloplasti ve SDG tekniklerinin uygulandığı görülmüştür. Bir sistematik derlemede farklı yumuşak doku cerrahi prosedürlerinin osseointegre, iyileşme başlı̆̆ takılı ve/veya yüklenmiş implantların etrafında keratinize dişeti genişliğini ve/veya yumuşak doku hacmini artırmaya yönelik etkinliği değerlendirilmiştir. Sonuç olarak SDG, subepitelyal bağ dokusu grefti veya ksenograft materyali gibi apikale pozisyone yarım kalınlıklı flap ile kombine edilen üç yöntemin de keratinize dişeti genişliğini artırmada etkili olduğu belirtilmiştir ${ }^{23}$. Bir başka sistematik derlemede farklı yumuşak doku ogmentasyon/düzeltme yöntemlerinin peri implant keratinize mukoza genişliğini ve/veya ikinci aşama cerrahide yumuşak doku hacmi kazancını artırma açısından etkinlikleri değerlendirilmiştir ${ }^{24}$. Lokalizasyona (maksilla, mandibula, ön veya lateral) ve klinik duruma (mevcut keratinize dişeti ve yumuşak doku hacmi) göre farklı ikinci-aşama tekniklerin kullanılabileceği belirtilmiştir. İmplant çevresi keratinize doku genişliğinin artırılması açısından, maksillada apikale pozisyone yarım kalınlıklı flebin, alt çenede apikale pozisyone yarım kalınlıklı flap/vestibüloplasti ile kombine SDG veya ksenogreft materyalinin kabul edilebilir sonuçlar sağladığı bildirilmiştir. Yumuşak doku hacmini artırmak için de maksillada roll flebin, veya üst ve alt çenede apikale pozisyone yarım kalınlıklı flap+ subepitelyal bağ dokusu greft uygulamasının güvenilir tedavi seçenekleri olduklarını belirt- 
J Biotechnol and Strategic Health Res. 2021;5(2):113-118

mişlerdir ${ }^{24}$. Bizim çalışmamızda maksillada ilave cerrrahi gereksinimi olmadığı görülürken, mandibular anterior ve posterior bölgelerde vestibüloplasti ve SDG yöntemlerine ihtiyaç duyulduğu görülmektedir. Keratinize doku genişliğinin bireyden bireye ve dentisyonun farklı bölgelerinde değişiklik gösterdiği mandibulada maksilladan daha az olduğu, bilinmektedir. ${ }^{25,26}$ Ayrıca yüksek frenilum ve kas bağlantılarının genellikle yetersiz keratinize dişeti genişliği ile ilişkili olduğu bilinmektedir. Bu sebeplerden dolayı, çalışmamızda da olduğu gibi implant çevresi dişeti sağlığının sürdürülebilmesi için ilave cerrahi işlemlerin gereksinimi alt çenede daha sık olabilir.

Retrospektif çalışma dizaynı sebebi ile keratinize dişeti genişliği ve yumuşak doku kalınlıklarının değerlendirilememiş olması çalışmamızın limitasyonudur.

Dental implantların başarısında, implant çevresindeki yumuşak doku yönetimi oldukça önemlidir. Yumuşak doku yönetiminde ilgili çeneye (maksilla/mandibula), bölgeye (anterior/posterior), vakanın gereksinimine (keratinize dişeti genişliği/ yumuşak doku hacmini artırma) ve klinisyenin tecrübesine dayanarak uygun cerrahi prosedürün seçilmesi klinik önem taşımaktadır.

\section{TEŞEKKÜR}

Yazarlar, King Faisal Üniversitesi Diş Hekimliği Fakültesi'nden Dr. Muhammad Adeel Ahmed'e ve arkadaşlarına verdikleri desteklerden dolayı teşekkür etmektedir. 
J Biotechnol and Strategic Health Res. 2021;5(2):113-118

\section{References}

1. Mazzotti C, Stefanini M, Felice P, et al. Soft-tissue dehiscence coverage at peri-implant sites. Periodontol 2000 2018;77:256-272.

2. Caton JG, Armitage G, Berglundh T, et al. A new classification scheme for periodontal and peri-implant diseases and conditions - Introduction and key changes from the 1999 classification. J Clin Periodontol 2018;45 Suppl 20:S1-S8.

3. Jung RE, Herzog M, Wolleb K, et al. A randomized controlled clinical trial comparing small buccal dehiscence defects around dental implants treated with guided bone regeneration or left for spontaneous healing. Clin Oral Implants Res 2017;28:348-354.

4. Schwarz F, Sahm N, Becker J. Impact of the outcome of guided bone regeneration in dehiscence-type defects on the long-term stability of peri-implant health: clinical observations at 4 years. Clin Oral Implants Res 2012;23:191-196.

5. Hammerle CHF, Tarnow D. The etiology of hard- and soft-tissue deficiencies at dental implants: A narrative review. J Clin Periodontol 2018;45 Suppl 20:S267-S277.

6. Puisys A, Linkevicius T. The influence of mucosal tissue thickening on crestal bone stability around bone-level implants. A prospective controlled clinical trial. Clin Oral Implants Res 2015;26:123-129.

7. Saglam E, Köseoğlu S. Peri-implant sert ve yumuşak doku eksiklikleri. Periodontal Hastalıkların Sınıflandırılması, 1. Baskı, cilt 7, Ertuğrul AS, Dikilitaş A (Ed), Ankara. Türkiye Klinikleri, 2021;s 63-70.

8. Giannobile WV, Jung RE, Schwarz F, Groups of the 2nd Osteology Foundation Consensus M. Evidence-based knowledge on the aesthetics and maintenance of peri-implant soft tissues: Osteology Foundation Consensus Report Part 1-Effects of soft tissue augmentation procedures on the maintenance of peri-implant soft tissue health. Clin Oral Implants Res 2018;29 Suppl 15:7-10.

9. Lin GH, Chan HL, Wang HL. The significance of keratinized mucosa on implant health: a systematic review. J Periodontol 2013;84:1755-1767.

10. Souza AB, Tormena M, Matarazzo F, et al. The influence of peri-implant keratinized mucosa on brushing discomfort and peri-implant tissue health. Clin Oral Implants Res 2016;27:650-655.

11. Baltacioglu E, Bagis B, Korkmaz FM, et al. Peri-Implant Plastic Surgical Approaches to Increasing Keratinized Mucosa Width. J Oral Implantol 2015;41:e73-81.

12. Chackartchi T, Romanos GE, Sculean A. Soft tissue-related complications and management around dental implants. Periodontol 2000 2019;81:124-138.

13. Langer B, Sullivan DY. Osseointegration: its impact on the interrelationship of periodontics and restorative dentistry. Part 3. Periodontal prosthesis redefined. Int J Periodontics Restorative Dent 1989;9:240-261
14. Langer B, Langer L. Overlapped flap: a surgical modification for implant fixture installation. Int J Periodontics Restorative Dent 1990;10:208-215.

15. Wennstrom JL, Derks J. Is there a need for keratinized mucosa around implants to maintain health and tissue stability? Clin Oral Implants Res 2012;23 Suppl 6:136-146.

16. Esposito M, Maghaireh H, Grusovin MG, et al. Soft tissue management for dental implants: what are the most effective techniques? A Cochrane systematic review. Eur J Oral Implantol 2012;5:221-238

17. Heitz-Mayfield LJ. Peri-implant diseases: diagnosis and risk indicators. J Clin Periodontol 2008;35:292-304.

18. Roccuzzo M, Grasso G, Dalmasso P. Keratinized mucosa around implants in partially edentulous posterior mandible: 10-year results of a prospective comparative study. Clin Oral Implants Res 2016;27:491-496.

19. Cairo F, Pagliaro U, Nieri M. Soft tissue management at implant sites. J Clin Periodontol 2008;35:163-167.

20. Thoma DS, Benic GI, Zwahlen M, et al. A systematic review assessing soft tissue augmentation techniques. Clin Oral Implants Res 2009;20 Suppl 4:146-165.

21. Lin CY, Chen Z, Pan WL, et al. Impact of timing on soft tissue augmentation during implant treatment: A systematic review and meta-analysis. Clin Oral Implants Res 2018;29:508-521.

22. Hamurcu N, Tunç S, Binici K, et al. Augmentation of Implant Sites with Insufficient Keratinised Mucosa by Autogenous Soft Tissue Grafting. KSU Medical Journal 2020;15:116124.

23. Bassetti RG, Stahli A, Bassetti MA, et al. Soft tissue augmentation around osseointegrated and uncovered dental implants: a systematic review. Clin Oral Investig 2017;21:53-70.

24. Bassetti RG, Stahli A, Bassetti MA, et al. Soft tissue augmentation procedures at second-stage surgery: a systematic review. Clin Oral Investig 2016;20:1369-1387.

25. Fiorellini, J.P., Kim, D. M., Uzel, N. G. (2011a). Anatomy of Periodontium. Newman MG, T. H., Klokkevold PR, Carranza AF (Ed.). Carranza’s Clinical Periodontology (11th ed. pp. 12-27). Philadelphia: WB Saunders.

26. Bowers, G. M. (1963). A Study of the Width of Attached Gingiva. Journal of Periodontology. 43(3), 201-209. doi: 10.1902/jop.1963.34.3.201 